\title{
KAMPOENG PELANGI: KAMPUNG VERTIKAL UNTUK MASYARAKAT BERPENGHASILAN RENDAH
}

\author{
Alvin $^{1)}$, Franky Liauw ${ }^{2 l}$ \\ 1)Program Studi S1 Arsitektur, Fakultas Teknik, Universitas Tarumanagara, alvinrichardy@gmail.com \\ 2) Program Studi S1 Arsitektur, Fakultas Teknik, Universitas Tarumanagara, frankyl@ft.untar.ac.id
}

\begin{abstract}
Abstrak
Gejala yang mengkawatirkan dan mendukung ketidak seimbangan lingkungan hidup adalah pertumbuhan penduduk yang tinggi. Adanya pertumbuhan penduduk membuat kebutuhan akan hunian terus meningkat, permasalahannya fasilitas yang disediakan oleh pemerintah dan pengembang hanya dapat dijangkau oleh kalangan menengah keatas saja, sedangkan seharusnya setiap penduduk memiliki hak untuk memiliki tempat tinggal tak terkecuali masyarakat berpenghasilan rendah (MBR). Kebudayaan dan tradisi masyarakat sebuah kampung yang kental dengan aktivitas dan kehidupannya semakin pudar setelah perkembangan ke arah hunian-hunian yang vertikal, tertutup dan individualistik. Kalianyar merupakan daerah terpadat di DKI Jakarta, hidup di tengah kesesakan sudah jadi lahapan sehari-hari. Selain warga asli, banyak pula pendatang dari luar Jakarta dan Jawa yang memilih Kalianyar, Tambora sebagai wilayah untuk mereka tempati sementara. Tak dipungkiri bahwa kepadatan penduduk di Kalianyar menimbulkan permasalahanpermasalahan hunian dan permintaan rumah tinggal. Maka dari itu, Kampoeng Pelangi hadir untuk membuat hidup warga Kalianyar lebih baik, indah dan harmoni. membuat sebuah hunian vertikal dengan pendekatan arsitektur fleksibel dan pembangunan berkelanjutan yang dapat mencerminkan, meningkatkan dan memenuhi kebutuhan dan kehidupan sebuah kampung di daerah Kelurahan Kalianyar. Menerapkan hidup yang berkelanjutan dalam aspek sosial, ekonomi, dan lingkungan dalam rupa kampung vertikal serta menerapkan arsitektur fleksibel dalam wujud fleksibilitas ruang.
\end{abstract}

Kata kunci: Fleksibel; Kampung Vertikal; MBR; Pembangunan Berkelanjutan; Pertumbuhan Penduduk

\begin{abstract}
A worrying symptom and supporting environmental imbalance is high population growth. The existence of population growth makes the need for housing continues to increase, the problem is that the facilities provided by the government and developers can only be reached by the upper middle class, while every resident should have the right to have a place to live, including low-income people (MBR). The culture and traditions of the people of a village that are thick with activities and their lives are fading after the development towards vertical, closed and individualistic dwellings. Kalianyar is the most densely populated area in DKI Jakarta, living in the midst of crowds has become a daily pastime. In addition to the natives, many migrants from outside Jakarta and Java chose Kalianyar, Tambora as their temporary residence. It is undeniable that the population density in Kalianyar creates housing problems and the demand for housing. Therefore, Kampoeng Pelangi is here to make the lives of Kalianyar residents better, more beautiful and harmonious. create a vertical residence with a flexible architectural approach and sustainable development that can reflect, improve and fulfill the needs and life of a village in the Kalianyar Village area. Implementing sustainable living in social, economic, and environmental aspects in the form of a vertical village and applying flexible architecture in the form of space flexibility.
\end{abstract}

Keywords: Flexible; MBR; Population growth; Sustainable Development; Vertical Village 


\section{PENDAHULUAN}

\section{Latar Belakang}

Jumlah populasi manusia akan terus bertambah setiap saat di suatu daerah atau wilayah. Salah satu sifat yang dimiliki oleh manusia yaitu adanya pertumbuhan yang cepat jika dibandingkan dengan makhluk lain. Pertumbuhan penduduk ini dapat dipengaruhi oleh tiga faktor penting yaitu tingkat kelahiran, tingkat kematian, dan tingkat perpindahan penduduk (Sudarsono, 1983). Berdasarkan hasil SP2020, jumlah penduduk Indonesia pada tahun 2020 mencapai 270,2 juta jiwa dengan rata - rata laju pertumbuhan penduduk sebesar 1,25 persen per tahun, pertumbuhan ini dipengaruhi oleh faktor kelahiran, kematian, dan juga migrasi. Dengan luas yang hanya sebesar 7 persen dari total luas wilayah Indonesia, Pulau Jawa menjadi pulau terpadat dengan dihuni oleh 151,6 juta jiwa atau 56,10 persen penduduk Indonesia dengan Ibukota Jakarta memiliki kepadatan penduduk paling tinggi yaitu sebesar 15.900 per Km2 (Humas, 2021). Jika dilihat persebaran kepadatan penduduk di seluruh kota Indonesia belum merata dan ini disebabkan oleh ledakan penduduk. Salah satu penyebab ledakan penduduk paling besar ditimbulkan oleh urbanisasi, menurut (Gambar 1), penduduk Indonesia yang akan tinggal di perkotaan mencapai 85 persen di tahun 2050.

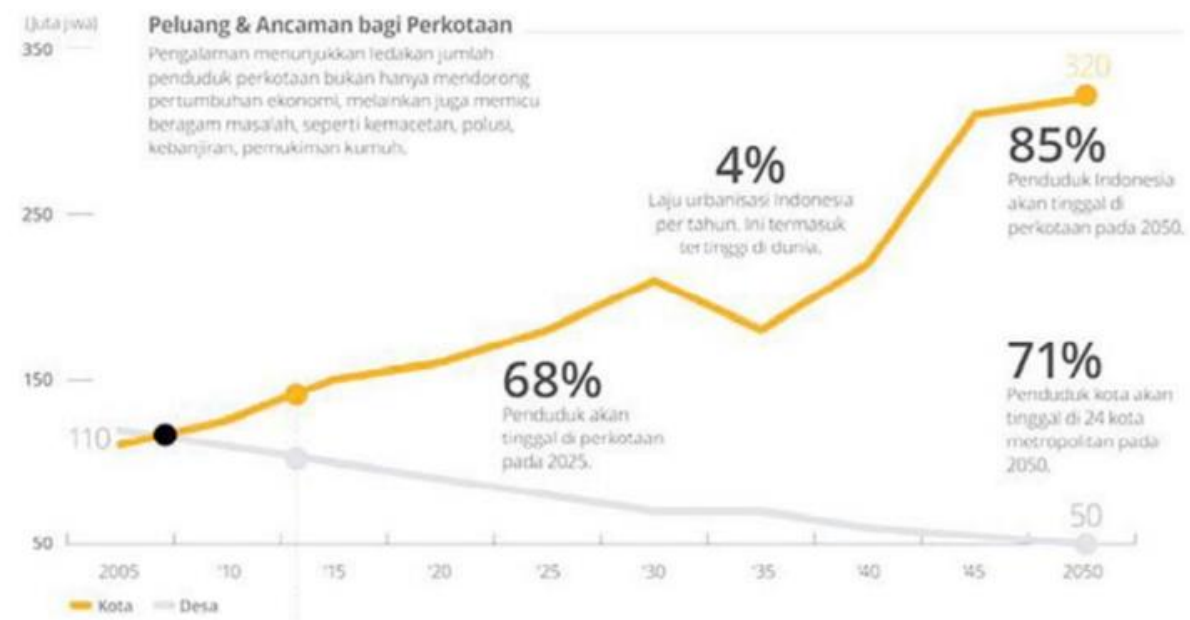

Gambar 1. Perkiraan Persebaran Penduduk Indonesia.

Sumber: (Suminar, 2017)

Kependudukan menjadi salah satu faktor penyebab timbulnya masalah hunian, adanya pertumbuhan penduduk membuat kebutuhan akan tempat tinggal meningkat. Jika kebutuhan fasilitas hunian dan rumah tinggal tidak sebanding dengan pertumbuhan penduduk, maka akan mengakibatkan kepadatan rumah yang tinggi dan kualitas hidup yang menurun. Permasalahan yang ada saat ini adalah kurangnya fasilitas rumah tinggal bagi masyarakat berpenghasilan rendah. Fasilitas yang disediakan oleh pemerintah dan pengembang hanya dapat dijangkau oleh kalangan menengah keatas saja. Ketersediaan lahan yang semakin menipis juga membuat harga tanah semakin mahal dan membuat suplai rumah bagi masyarakat berpenghasilan rendah menjadi terbatas. Dengan rendahnya daya beli/sewa masyarakat berpenghasilan rendah membuat permintaan rumah tinggal meningkat setiap tahunnya.

Menurut UU No. 1 Tahun 2011, setiap penduduk memiliki hak asasi yang sama untuk memiliki tempat tinggal sebagai kebutuhan dasar tak terkecuali untuk masyarakat berpenghasilan rendah. Terdapat beberapa solusi seperti program rumah susun dan kampung deret, tetapi keduanya dianggap masih belum dapat menjadi solusi permasalahan rumah tinggal. Pada progam rumah susun, pembangunan vertikal jelas menjadi solusi permasalahan keterbatasan lahan, tetapi tidak mencerminkan perilaku sebuah kampung. Menurut Indonesia Property Expo 2018 (Katharina, 2018), Kementrian PUPR merumuskan beberapa masalah rumah susun. 
Sedangkan program kampung deret, perilaku dari sebuah kampung masih terjaga bahkan menjadi lebih baik akibat adanya penataan, tetapi permasalahan keterbatasan lahan dan kepadatan penduduk yang terus meningkat masih menjadi permasalahan. Hal ini yang menjadi permasalahan dalam membangun hunian vertikal, dimana ciri - ciri dan kebutuhan dari sebuah kampung tidak diikutsertakan bersama dengan perpindahan penghuninya.

\section{Rumusan Masalah}

Kelurahan Kalianyar menjadi daerah terpadat di Kecamatan Tambora dengan kepadatan penduduk $92.900 \mathrm{jiwa} / \mathrm{km} 2$, bahkan menjadi daerah terpadat di DKI Jakarta (BPS, 2019). Lahan yang sudah tidak ada tidak diimbangi dengan pertumbuhan dan kepadatan penduduk mengakibatkan adanya permasalahan hunian serta permasalahan lainnya. Menurut Rencana Tata Ruang Wilayah 2030 pasal 140, Kelurahan Kalianyar masuk ke dalam status kawasan pemukiman kumuh berat yang harus segera diperbaiki, mengarah ke pengembangan kawasan perumahan vertikal sebagai penyediaan perumahan golongan menengah kebawah.

\section{Tujuan}

Berdasarkan latar belakang dan rumusan masalah, proyek ini bertujuan untuk membuat sebuah hunian vertikal yang dapat mencerminkan, meningkatkan dan memenuhi kebutuhan dan kehidupan sebuah kampung di Kelurahan Kalianyar dalam aspek sosial, ekonomi, dan lingkungan berupa kampung vertikal.

\section{KAJIAN LITERATUR}

\section{Ekologi}

Kata ekologi diciptakan oleh ahli zoologi Jerman Ernst Haeckel, ekologi adalah ilmu yang mempelajari hubungan interaksi antara makhluk hidup dengan lingkungan disekitarnya. Kata ekologi berasal dari bahasa Yunani, yaitu oikos dan logos. Oikos memiliki arti rumah tinggal, sedangkan logos memiliki arti ilmu sehingga dapat dikatakan bahwa ekologi adalah ilmu yang mempelajari makhluk hidup di tempat tinggalnya. Bahkan ekologi juga dikenal sebagai ilmu yang mempelajari rumah tangga makhluk hidup (Wikipedia, 2021). Salah satu permasalahan ekologi yang mengkhawatirkan dan membuat lingkungan tidak seimbang saat ini adalah pertumbuhan / ledakan penduduk. Permasalahan ini dapat mengakibatkan perubahan lingkungan yang akan berdampak pada kehidupan manusia, baik dampak positif maupun negatif. Dalam pemecahannya, masalah ekologi ini tidak hanya dapat dilihat dari satu aspek saja, tetapi harus mempertimbangkan beberapa aspek yang terdiri dari sosial, ekonomi, dan lingkungan sebagai komponen pembangunan berkelanjutan (Utina, 2008).

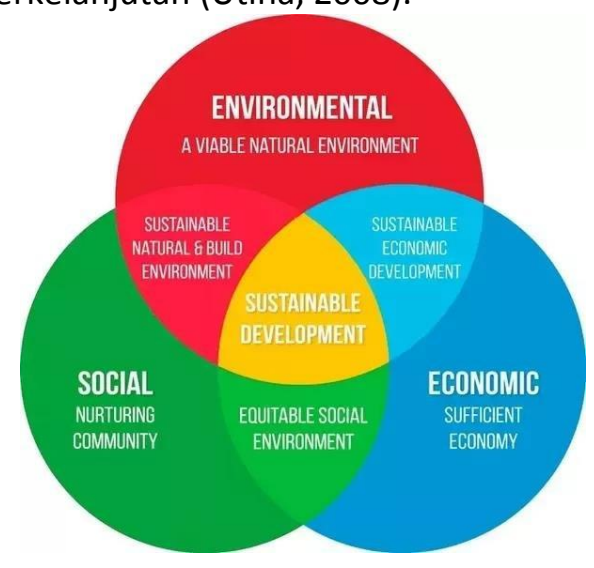

Gambar 2. Diagram Komponen Pembangunan Berkelanjutan.

Sumber: (SSLA, 2021) 


\section{Kampung}

Kampung adalah Kawasan hunian masyarakat berpenghasilan rendah yang memiliki kondisi fisik kurang baik (Budiharjo, 1992). Kampung adalah suatu kesatuan lingkungan tempat tinggal yang dihuni oleh sekelompok masyarakat yang terdiri dari kesatuan keluarga - keluarga. Kampung adalah satu - satunya jenis permukiman yang dapat menampung golongan penduduk dengan tingkat perekonomian dan Pendidikan paling rendah, namun tidak menutup kemungkinan bagi penduduk dengan tingkat perekonomian dan Pendidikan tinggi (Khudori, 2002). Kampung adalah organisasi sosial terkecil dalam sistem masyarakat Indonesia sehingga pada setiap kampung memiliki organisasi sosialnya masing - masing yang dibentuk oleh warga kampung tersebut untuk mengawasi dan mengatur tata tertib kemasyarakatan warga kampung yang bersangkutan (Rozak, 2017).

\section{Hunian Vertikal}

Menurut UU No. 1 Tahun 2011, Hunian vertikal adalah gedung bertingkat yang dibangun dalam suatu lingkungan yang terbagi dalam bagian-bagian yang distrukturkan secara fungsional dalam arah horizontal maupun vertikal dan merupakan satuan-satuan yang masing-masing dapat memiliki dan digunakan secara terpisah yang berfungsi sebagai tempat hunian yang dilengkapi dengan bagian bersama, benda bersama dan tanah bersama.

\section{Permasalahan Hunian Vertikal}

Menurut “Indonesia Property Expo 2018" (Katharina, 2018), Kementrian PUPR merumuskan beberapa permasalahan yang ada pada hunian vertikal:

a. Bangunan terlalu monoton.

b. Kurangnya udara dan pencahayaan alami.

c. Unitnya yang kecil dan sesak.

d. Unitnya yang tidak fleksibel, terlebih terhadap penambahan anggota keluarga.

e. Koridor yang sempit dan panjang.

f. Kurangnya ruang bersama.

g. Jauh dari fasilitas kesehatan.

h. Jauh dari fasilitas aktif.

i. Jauh dari faslitas Pendidikan.

j. Kurangnya ruang terbuka hijau.

\section{Kampung Vertikal}

Kampung Vertikal secara keseluruhan adalah kelompok hunian di wilayah tertentu yang berbentuk vertikal dan didominasi masyarakat menengah kebawah. Pada umunya kampung menempati lahan yang cukup luas, saat ini dengan lahan yang semakin padat, cukup sulit untuk menciptakan kampung baru. Lahan yang akan terbangun diminimalisir agar ruang terbuka hijau akan lebih banyak tersedia dan menciptakan kondisi lingkungan yang lebih baik.

Kampung Vertikal adalah tranformasi dari kampung eksisting tanpa menghilangkan karakter lokal, bentuk, material, volume, skyline bangunan, potensi ekonomi, kreativitas warga, dll. Kampung dibuat menjadi vertikal, tetapi kehidupan sebuah kampung tetap dipertahakankan. Kearifan lokal dan kreativitas warganya menjadi sumber daya utama bagi pengelolaan kampung vertikal. Kampung vertikal adalah arsitektur rakyat, yang dirancang lebih bersih, sehat, nyaman, dan kuat. Kampung vertikal bisa menjadi salah satu solusi bagi permasalahan penduduk dan kebutuhan tempat tinggal di masa yang akan datang dan merupakan wujud pelestarian dari keberadaan kampung yang mulai terkikis oleh zaman modern, terlebih lagi kampung vertikal dapat menjadi penyangga untuk perekonomian rakyat (Yu Sing, 2011). 


\section{Karakteristik Kampung Vertikal}

Menurut "Jakarta Vertical Kampung Master Class" dalam (Rozak, 2017), karakter kampung vertikal sebagai berikut:

a. Community (Masyarakat)

Karakteristik awal yang merupakan pembentuk sebuah kampung adalah komunitas.

b. Informality (Keinformalan)

Pada umunya sebuah kampung muncul dari keinformalan aturan - aturan yang sesuai dengan karakteristik masyarakatnya.

c. Affordability (Keterjangkauan)

Mempertimbangkan dari segi biaya dalam perancangan kampung, karena bangunan ini diperuntukan untuk golongan masyarakat menengah kebawah.

d. Identity (Identitas)

Nilai - nilai budaya yang ada dalam sebuah kampung menjadi suatu ciri khas atau identitas dari kampung itu sendiri.

e. Individuality (Kepribadian)

Kepribadian sebuah kampung tercermin dari kepribadian masing - masing penghuni, kepribadian itu dapat terbentuk tergantung dari manyarakat sekelilingnya.

f. Effeciency (Efisiensi)

Memanfaatkan lahan secara efisien dan sebaik mungkin mengingat lahan sebuah kampung terlalu padat. Tidak hanya itu, ruang-ruang harus multifungsi untuk menciptakan keefisiensian.

g. Diversity (Keanekaragaman)

Pada umunya sebuah kampung terdiri dari berbagai macam masyarakat. Di dalam kampung vertikal keberagaman menjadi kesatuan dan ciri khas kampung vertikal.

h. Participatory (Partisipasi)

Keterlibatan masyarakat merupakan salah satu unsur dari "Kampung Spirit" dimana adanya keterlibatan masyarakat dalam kegiatan yang ada di dalam sebuah kampung.

i. Linkage (Keterkaitan)

Dalam unsur kampung sebuah keterkaitan antara masing masing masyarakatnya yang ada pada umumnya sangat erat.

j. Collectivity (Kolektivitas)

Sebuah bentuk kerja sama yang dapat menghasilkan banyak nilai tambah dalam kehidupan bermasyarakat.

k. Space Experience (Pengalaman Ruang)

Pengalaman suasana ruang yang hadir merupakan ciri khas dari kampung itu sendiri, dimana terdapat banyak ruang untuk berbagi satu sama lainnya. Suasana kampung akan terlihat ketika keeratan masyarakat itu terjalin, dimana ada interaksi sosial didalamnya.

I. Human Scale (Skala Manusia)

Dalam sebuah kampung terdapat asas-asas kemanusiaan seperti skala manusia. Agar sesuai dengan dengan asas kampung yaitu kemanusiaan.

\section{Konsep Fleksibilitas Ruang}

Menurut "Dimensi Ruang dan Waktu" (Toekio, 2000), fasilitas kampung vertikal sebagai berikut:

a. Ekspansibilitas, yaitu memungkinkan perancangan ruang menampung pertumbuhan melalui perluasan, serta dapat berkembang terus sesuai kebutuhan penghuninya.

b. Konvertibilitas, yaitu memungkinkan adanya perubahan orientasi dan suasana dengan keinginan pelaku tanpa melakukan perombakan besar-besaran terhadap ruang yang sudah ada.

c. Versatilitas, yaitu dapat dilakukan melalui penggunaan ruang yang multifungsi yang mampu mewadahi beberapa kegiatan atau fungsi pada waktu yang berbeda, atau dapat mewadahi kegiatan sesuai waktu kebutuhannya dalam sebuah ruang yang sama. 


\section{METODE}

Pendekatan pertama yaitu mengidentifikasi ruang, aktivitas, perilaku, karakter dan permasalahan yang ada di Kelurahan Kalianyar dari segi aspek sosial, ekonomi, dan lingkungan. Pendekatan ini dilakukan dengan cara observasi di lapangan dan mencari data - data literatur di internet. Pendekatan ini dilakukan untuk mengetahui aktivitas, kebutuhan ruang, dan solusi yang dibutuhkan dalam proyek ini serta mengetahui aspek mana saja yang harus ditingkatkan untuk proses pembangunan berkelanjutan.

Pendekatan kedua yaitu perancangan arsitektur ruang fleksibel pada unit dagang dan hunian kampung vertikal. Pendekatan ini dilakukan dengan cara mengidentifikasi kebutuhan luas unit, kebutuhan ruang, dan kebutuhan luas ruang sebagai acuan dalam perancangan unit hunian fleksibel. Perancangan ini dilakukan untuk mengatasi permasalahan kenyamanan tinggal penghuni hunian vertikal dalam beraktivitas pada keterbatasan ruang.

\section{DISKUSI DAN HASIL}

\section{Identifikasi Kelurahan Kalianyar}

Dari observasi lapangan dan studi literatur di internet, terdapat beberapa kondisi ekonomi Kelurahan Kalianyar, antara lain:

a. MBR (Masyarakat Berpenghasilan Rendah)

Banyak masyarakat di Kelurahan Kalianyar yang merupakan masyarakat berpenghasilan rendah. Hal ini dikarenakan oleh penduduk yang umumnya banyak bekerja di sektor informal. Mereka berupah rendah sehingga tinggal dalam pemukiman yang padat, dan kumuhpun tidak terelakan lagi.

b. Pekerjaan Informal

Masyarakat Kelurahan Kalianyar bervariasi dalam mencari mata pencaharian, namun sebagian besar pekerjaan yang digeluti berpusat pada usaha mandiri. Hal ini berhubungan dengan banyaknya peluang usaha perniagaan di sekitar wilayah Kelurahan Kalianyar. Buruh dan pedagang menjadi pekerjaan yang paling banyak diminati. Usaha konveksi menjamur dan semakin banyak bertumbuh dari tahun ke tahun, jumlah usaha konveksi yang ada juga membuka peluang kerja bagi penduduk setempat yang bekerja menjadi buruh.

c. Hunian Sewa

Dengan penghasilan yang sangat kecil, banyak masyarakat Kelurahan Kalianyar yang menempati rumah tinggal dengan cara menyewa. Banyak rumah kontrakan dan kos kosan yang tersebar di seluruh area Kelurahan Kalianyar.

Dari observasi lapangan dan studi literatur di internet, terdapat beberapa kondisi sosial Kelurahan Kalianyar, antara lain:

a. Suka Bersosialisasi

Hubungan sosial antar masyarakat Kelurahan Kalianyar dapat dibilang baik. Hal ini dapat terlihat dari aktivitas masyarakat yang masih sering bersosialisasi satu dengan yang lain, entah itu hanya sekedar ngobrol ataupun kumpul. Kegiatan kerja bakti pun masih dilakukan di daerah ini.

b. Hidup Bersama

Bukan hanya dalam beraktivitas saja mereka bersama - sama. Hidup berhuni dalam rumah tinggal pun mereka bersama - sama. Akibat dari jumlah penduduk yang banyak dengan lahan yang terbatas membuat mereka harus tinggal bersama, sangat jarang ditemui rumah tinggal dengan $1 \mathrm{KK}$. Bahkan mereka harus menggunakan MCK bersama karena banyak rumah yang tidak mempunyai kamar mandi.

c. Budaya Betawi 
Suku asli masyarakat Kelurahan Kalianyar adalah suku betawi. Dari sejarah awal terlihat pertama kali orang yang tinggal di daerah ini adalah orang betawi, walaupun sekarang yang tinggal di daerah ini bukan suku betawi semua. Ondel - ondel pun masih sering terlihat mengamen di daerah ini.

Dari observasi lapangan dan studi literatur di internet, terdapat beberapa kondisi lingkungan Kelurahan Kalianyar, antara lain:

a. Lahan Sempit

Akibat jumlah yang melebihi kapasitas lahan ini membuat kepadatan penduduk menjadi sangat tinggi sehingga lahan pun menjadi terbatas dan sempit, selokan - selokan yang ada pun dipaksa tutup untuk dibuat area sirkulasi.

b. Sampah

Sampah menjadi salah satu permasalahan lingkungan yang ada di Kelurahan Kalianyar. Banyak masyarakat yang membuang sampah ke selokan.

c. Tidak Ada RTH

Luas wilayah Kelurahan Kalianyar yaitu 31,8 Ha dengan peruntukan tanah terdiri dari 65\% pemukiman dan $35 \%$ adalah perniagaan. Semua lahan tersebut kini sudah padat semua (Suminar, 2017). jangankan untuk RTH, untuk lahan rumah tinggal saja mereka kekurangan.

Dari data - data observasi dan internet diatas dapat disimpulkan bahwa terdapat beberapa aspek di Kelurahan Kalianyar yang masih dianggap kurang, aspek tersebut yaitu aspek ekonomi dan lingkungan sedangkan untuk aspek sosial sudah baik mengingat lokasi merupakan sebuah kampung yang pada umumnya interaksi sosial antar warganya masih terjalin erat. Walaupun begitu ketiga aspek ini akan tetap ditingkatkan, dari yang kurang menjadi baik dan yang sudah baik menjadi lebih baik lagi.

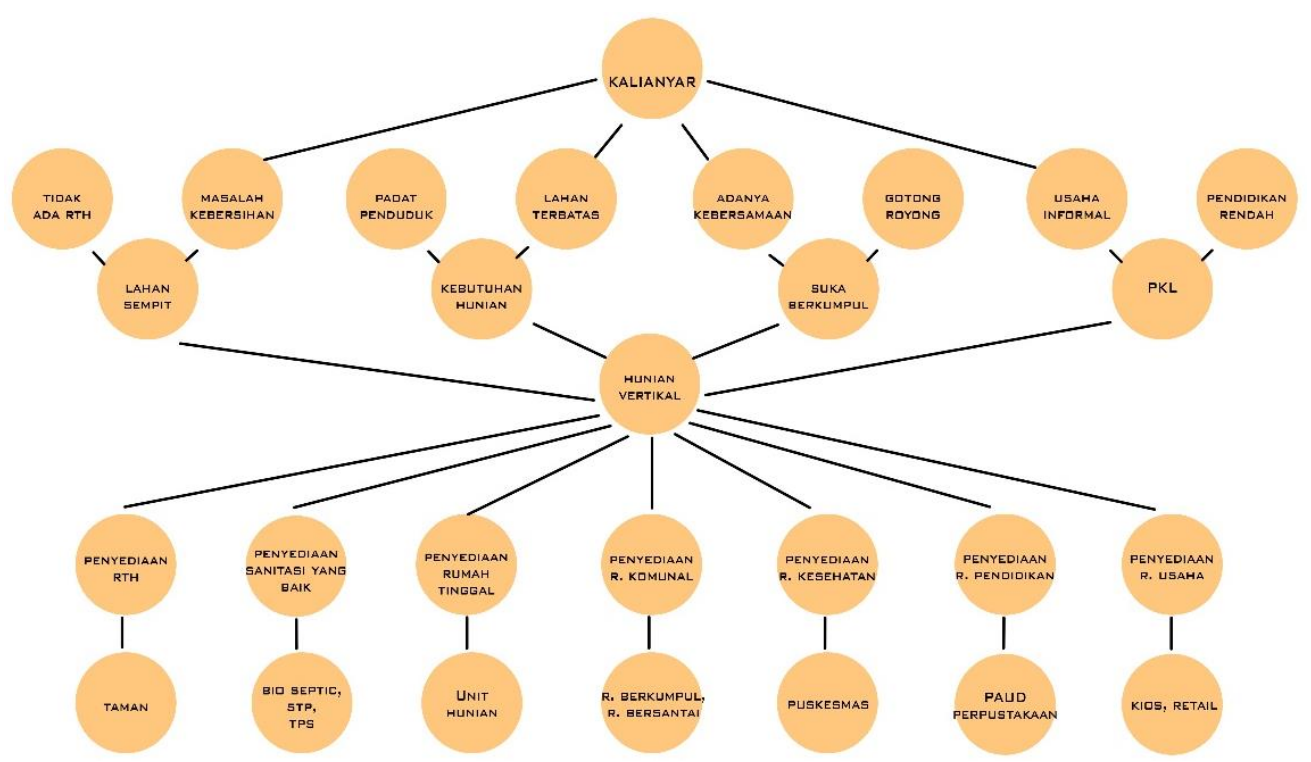

Gambar 3. Diagram Kebutuhan Ruang \& Aktivitas. Sumber: Analisa Pribadi

Lalu seperti(Gambar 3.) didapat kebutuhan ruang dan aktivitas yang muncul dari permasalahan dan kelebihan yang ada di Kelurahan Kalianyar. Pertama, permasalahan penduduk yang padat dan lahan yang terbatas menghasilkan hunian sebagai kebutuhan ruang paling penting. Lalu, dengan banyaknya usaha seperti, usaha rumah, industri, serta pkl, penyedian ruang untuk usaha juga menjadi penting untuk menopang aktivitas ekonomi warga maupun disekitarnya. Warga Kalianyar merupakan masyarakat yang senang untuk berkumpul sehingga penyediaan ruang 
komunal juga menjadi salah satu yang utama, dan permasalahan lingkungan dan sanitasi yang ada sehingga penyediaan sanitasi yang baik serta taman juga menjadi penting. Terdapat juga fasilitas kesehatan, Pendidikan, peribadatan, serta pemerintah sebagai fasilitas penunjang warga.

\section{Desain Perancangan}

Dilihat dari (Gambar 4.) sekitar Kampoeng Pelangi merupakan perumahan warga dengan tingkat rendah. Bangunan ini dapat menjadi salah satu landmark yang ada di Kelurahan Kalianyar. Letaknya yang dekat dengan jalan utama dapat menarik perhatian, berada di dalem gang dan dekat jalan utama membuat berjalan kaki menjadi trasnportasi yang lebih diprioritaskan. Kampoeng Pelangi dapat menjadi fasilitas dan destinasi baru di Kelurahan Kalianyar. Bukan hanya merancang area tapak, tetapi ruang sekitar juga ikut dirancang seperti salah satunya Kalianyar Promenade. Dengan adanya Kalianyar Promenade ini membuat kali ciliwung yang ada lebih hidup.

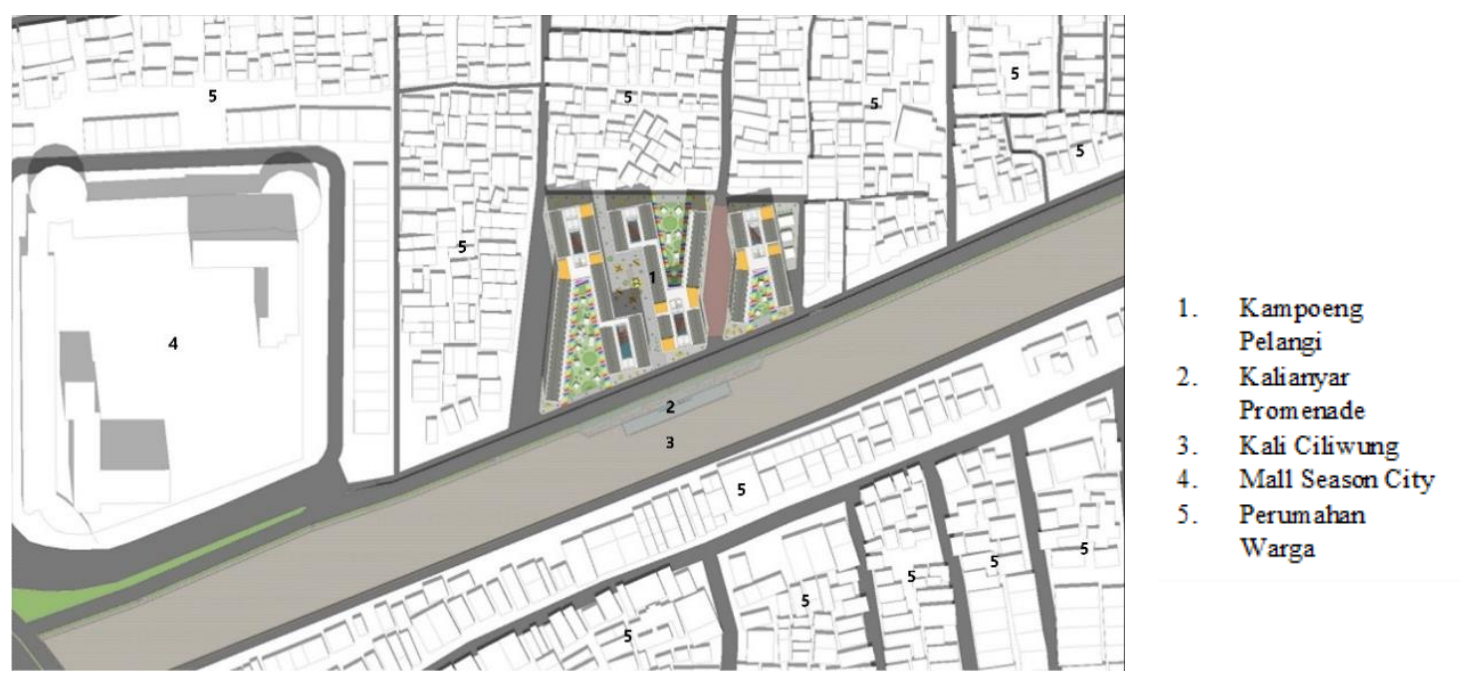

Gambar 4. Blockplan.

Sumber: Hasil Pribadi
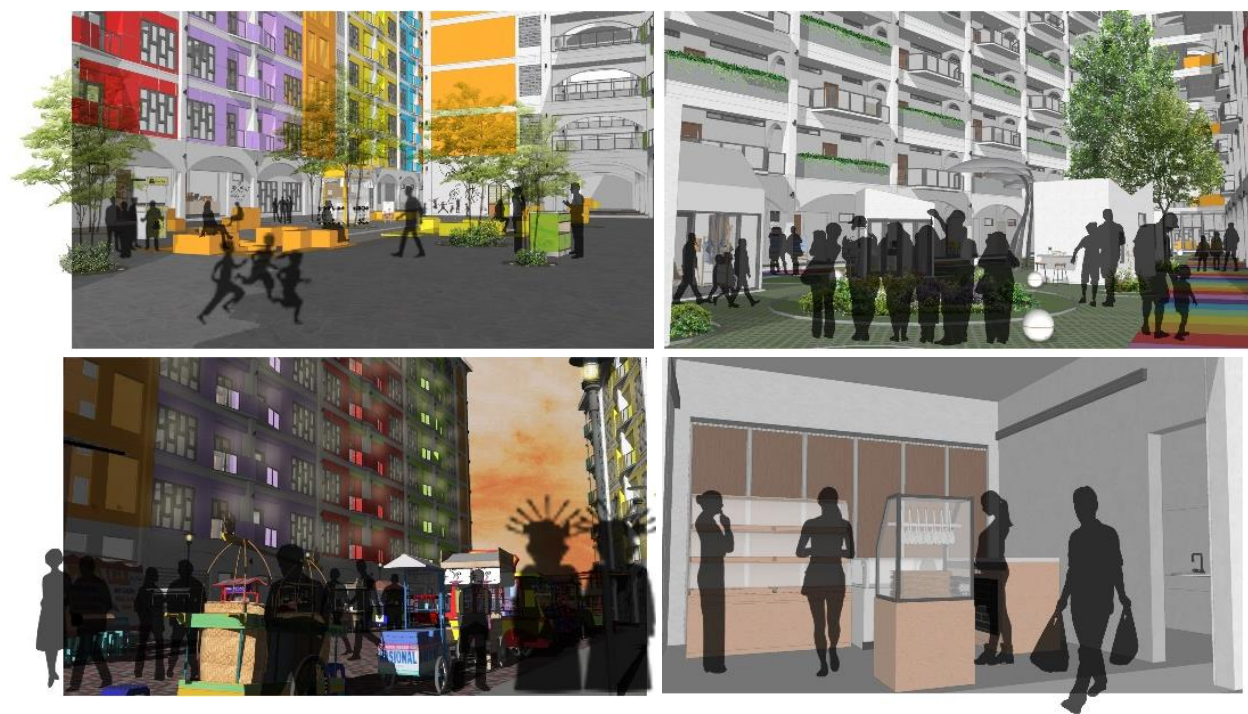

Gambar 5. Ruang - Ruang Pada Lt. Dasar. Sumber: Hasil Pribadi 
Kampoeng Pelangi dibagi menjadi tiga massa bangunan, dimana setiap antar bangunan terdapat ruang - ruang aktivitas. Pada lantai dasar merupakan pusat untuk aktivitas ekonomi, banyak disediakan juga ruang - ruang untuk bersosialisasi, serta taman - taman sebagai ruang hijau. Ruang hijau dan sosial bukan hanya sekedar untuk berkumpul dan bersantai tetapi juga ada aktivitas ekonomi disana. Pada lantai dasar terdapat unit dagang yang fleksibel sesuai kebutuhan aktivitas.
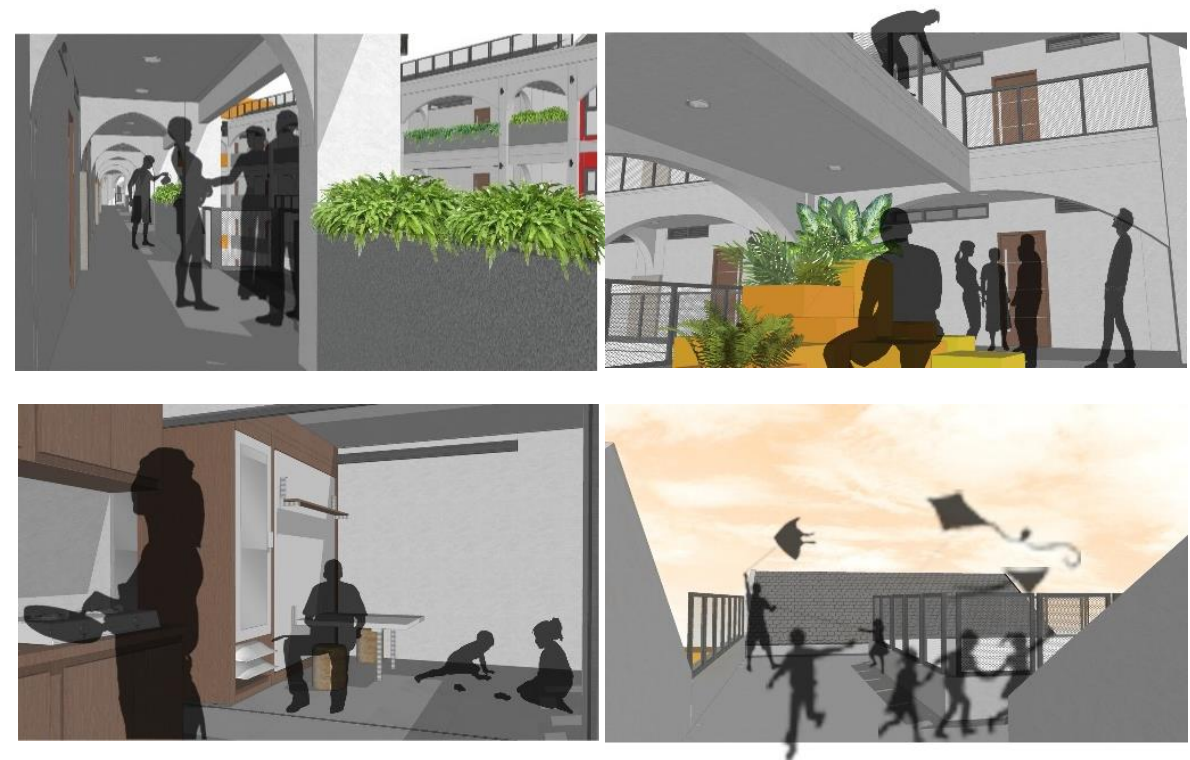

Gambar 6. Ruang - Ruang Pada Lt. Tipikal. Sumber: Hasil Pribadi

Terdapat dua tipe lantai tipikal, lantai tipikal genap dan lantai tipikal ganjil, keduanya hanya berbeda di letak balkon dan ruang bersamanya saja. Unit hunian merupakan unit yang fleksibel, disediakan balkon dan ruang bersama untuk penghuni bersosialisasi khususnya pada sore hari, serta adanya pos ronda untuk berjaga seperti sebuah kampung pada umumya. Banyak ruang yang didesain void agar interaksi antar penghuni tiap lantai tetap terjaga. Pembatas railing berupa planter box untuk penghijauan serta aktivitas berkebun. Pada lantai rooftop, selain untuk tempat sevis, lantai ini juga dapat digunakan untuk aktivitas bersama seperti bermain layang - layang.

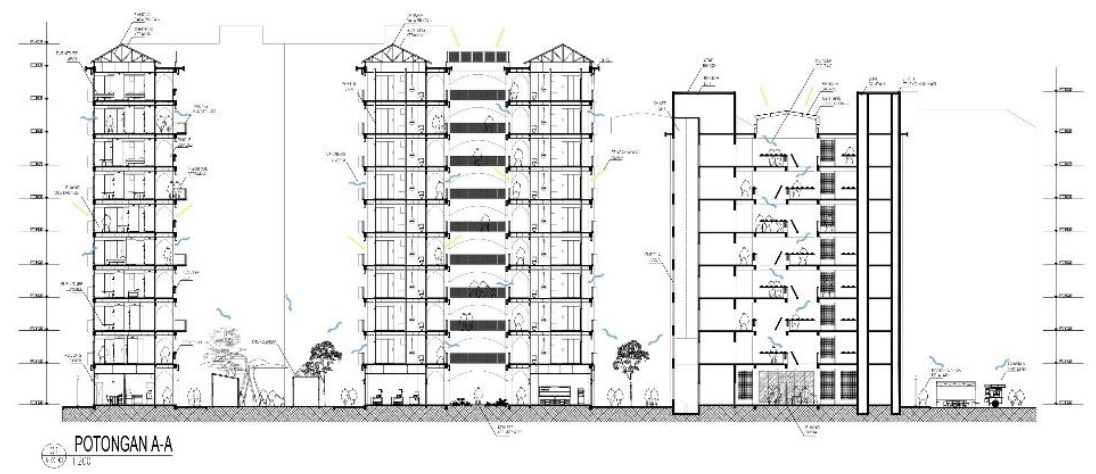

Gambar 7. Potongan.

Sumber: Hasil Pribadi

Jumlah lantai tiap bangunan dibuat berbeda untuk sirkulasi matahari dan udara alami serta kenyamanan penghuni sekitar. Bangunan menggunakan sistem single loaded agar adanya pencahayaan dan pengudaraan silang. Setiap ruang memiliki aktivitas sehingga tidak ada ruang kosong. Warna - warna yang ada pada bangunan diambil dari warna yang ada pada pelangi. 


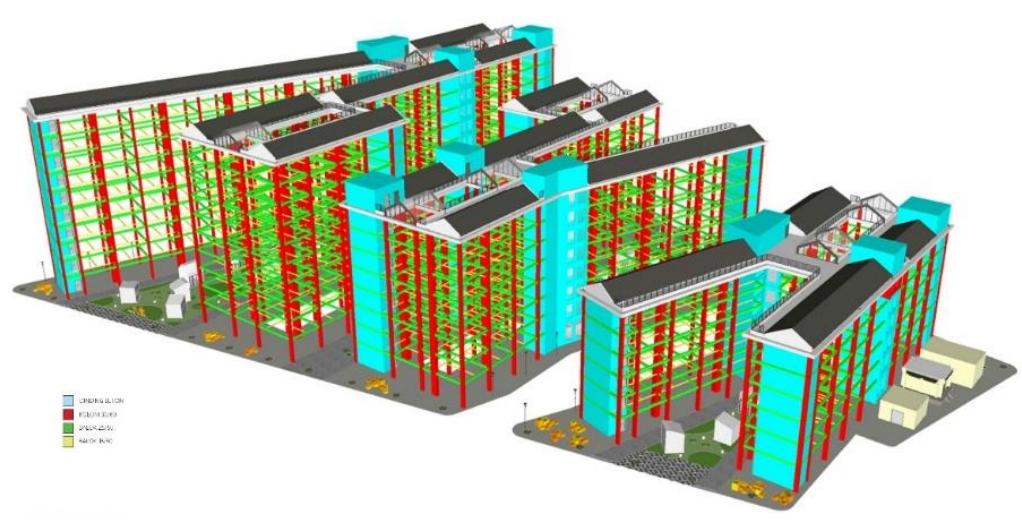

Gambar 8. Aksonometri Struktur Sumber: Hasil Pribadi

Untuk struktur, bangunan menggunakan struktur konvensional pada umumnya berupa dinding beton sebagai core bangunan, lalu ada kolom serta balok beton sebagai pendukung struktur. Untuk bagian atap menggunakan struktur rangka baja ringan.

\section{Luas Unit}

Standar luas minimal di setiap negara berbeda-beda, tergantung pada tingkat ekonomi, sosial budaya dan iklim yang ada. Di Indonesia, standar kebutuhan luas minimal hunian sederhana diatur dalam SNI 03-1733-2004 dan digunakan oleh pemerintah sebagai dasar menentukan luas hunian sederhana yang mendapatkan subsidi. Standar ini berdasarkan pada Neufret Data Arsitek dimana kebutuhan luas ruang dihitung berdasarkan kebutuhan udara segar dalam ruangan. Berdasarkan SNI 03-1733-2004, luas minimal rumah sederhana (asumsi 1 keluarga terdiri atas 4 orang) adalah $36 \mathrm{~m}^{2}$ atau $9 \mathrm{~m}^{2}$ per jiwa. Setiap Unit akan menggunakan metode arsitektur fleksibel, dimana dengan luas terbatas yang hanya $36 \mathrm{~m}^{2}$ penghuni dapat mengatur luas sesuai dengan kebutuhan mereka sehingga luas bisa fleksibel dan tidak sesak. 


\section{Kebutuhan \& Luas Ruang}

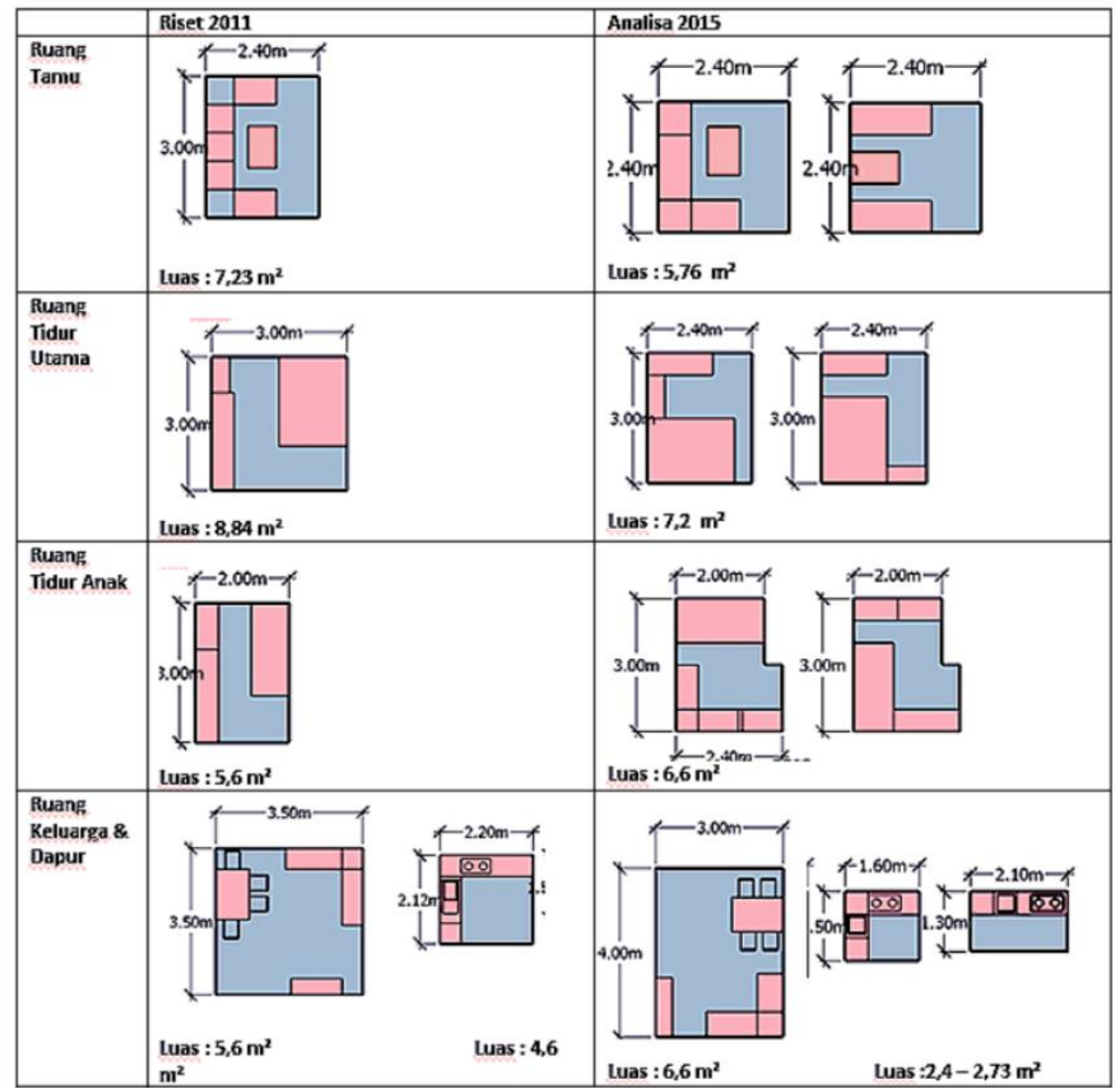

Gambar 9. Tabel Konfigurasi Ruang Sumber: (Suryo, 2017)

Pada (Gambar 9.) terdapat kebutuhan ruang yang ada pada unit hunian vertikal dimana masing - masing ruang terdapat juga luas minimal ruangan untuk kenyamanan para penghuninya. Ini akan menjadi acuan dalam mendesain unit hunian fleksibel dimana nantinya ruang - ruang ini dapat diubah dan disesuaikan terhadap kebutuhan luas dan aktivitas penghuninya.

\section{Unit Hunian Fleksibel}

Unit Hunian Fleksibel memiliki luas $36 \mathrm{~m}^{2}$ yang terbagi menjadi 2 zona yaitu zona servis dan zona fleksibel. Pada zona servis terdapat ruang seperti kamar mandi, dapur, balkon dan r. cuci jemur. Pada unit ini dapat menghasilkan beberapa kemungkinan denah sesuai penghuninya. Pada zona fleksibel dapat digunakan sebagai kamar tidur, r. kerja, r. keluarga, r. makan, r. bermain, dll sesuai dengan aktivitas yang ingin dilakukan. Pada zona fleksibel ini terdapat unit furniture fleksibel yang digunakan sebagai perabot untuk menunjang aktivitas serta sebagai pembatas ruang yang dapat digerakan. Untuk menutup ruang - ruang fleksibel yang ada disediakan partisi lipat yang kedap suara sebagai penutup ruangan. 


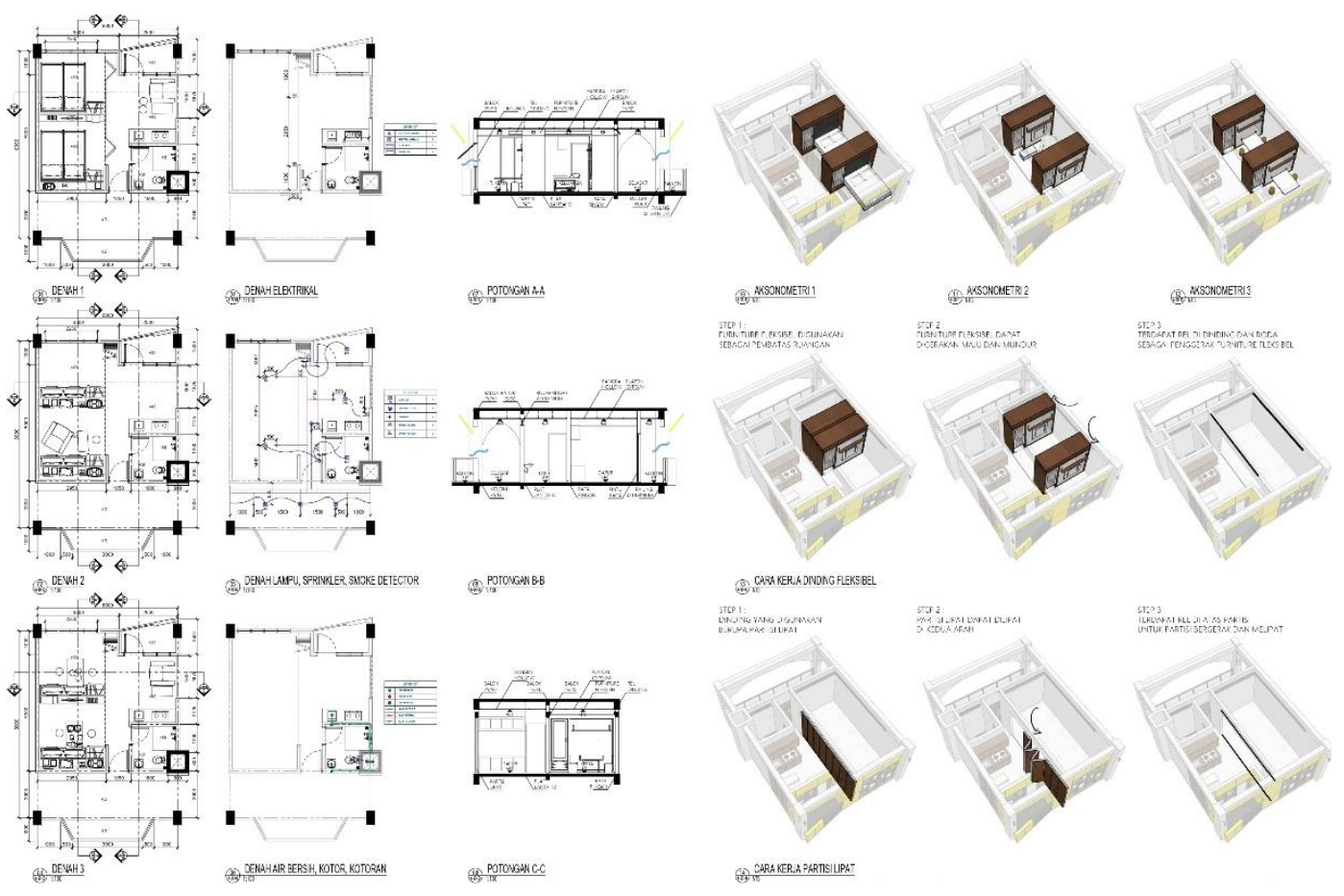

Gambar 10. Diagram Unit Hunian Fleksibel.

Sumber: Hasil Pribadi

\section{Unit Furniture Fleksibel}

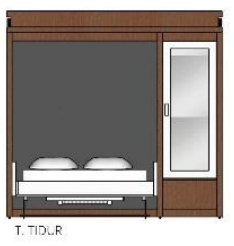

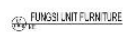
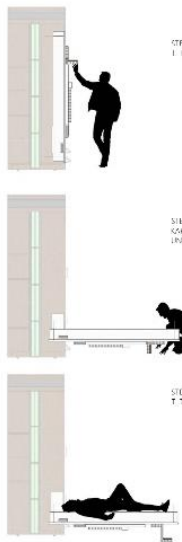

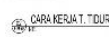
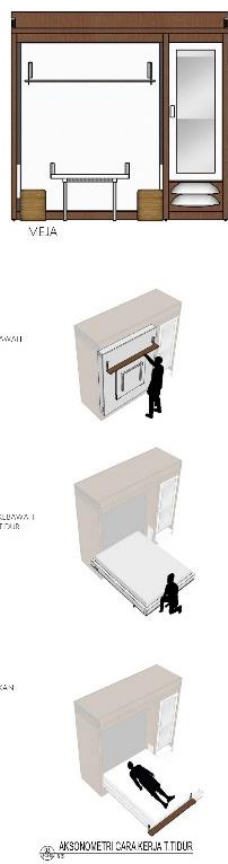
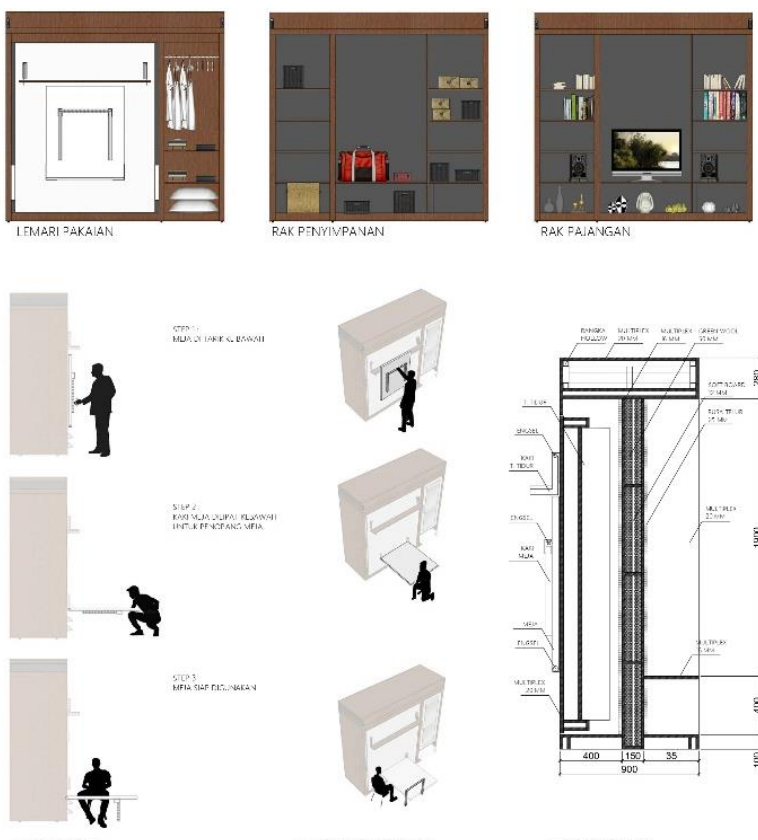

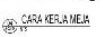
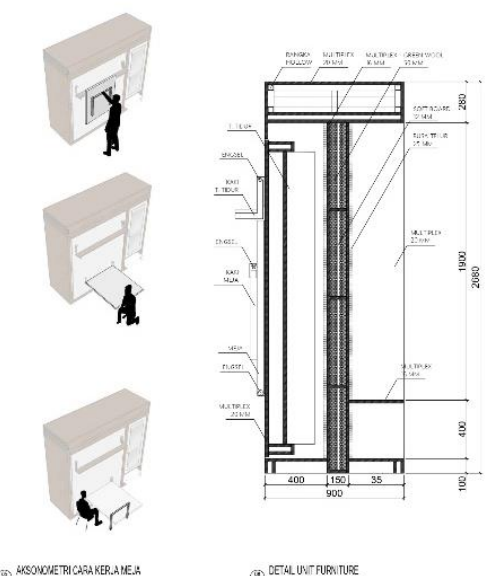

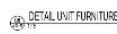

Gambar 11. Diagram Unit Furniture Fleksibel.

Sumber: Hasil Pribadi

Unit Furniture sendiri memiliki beberapa fungsi furniture yaitu sebagai t. tidur, lemari pakaian, meja, kerja, meja makan, rak pajangan dan rak penyimpanan yang digabung menjadi satu unit furniture fleksibel. Sistem perabotannya menggunakan sistem lipat dimana nantinya unit furniture ini dapat digerakan ke arah depan dan belakang menggunakan roda yang ada pada bawah unit dan rel yang menempel di tembok. 


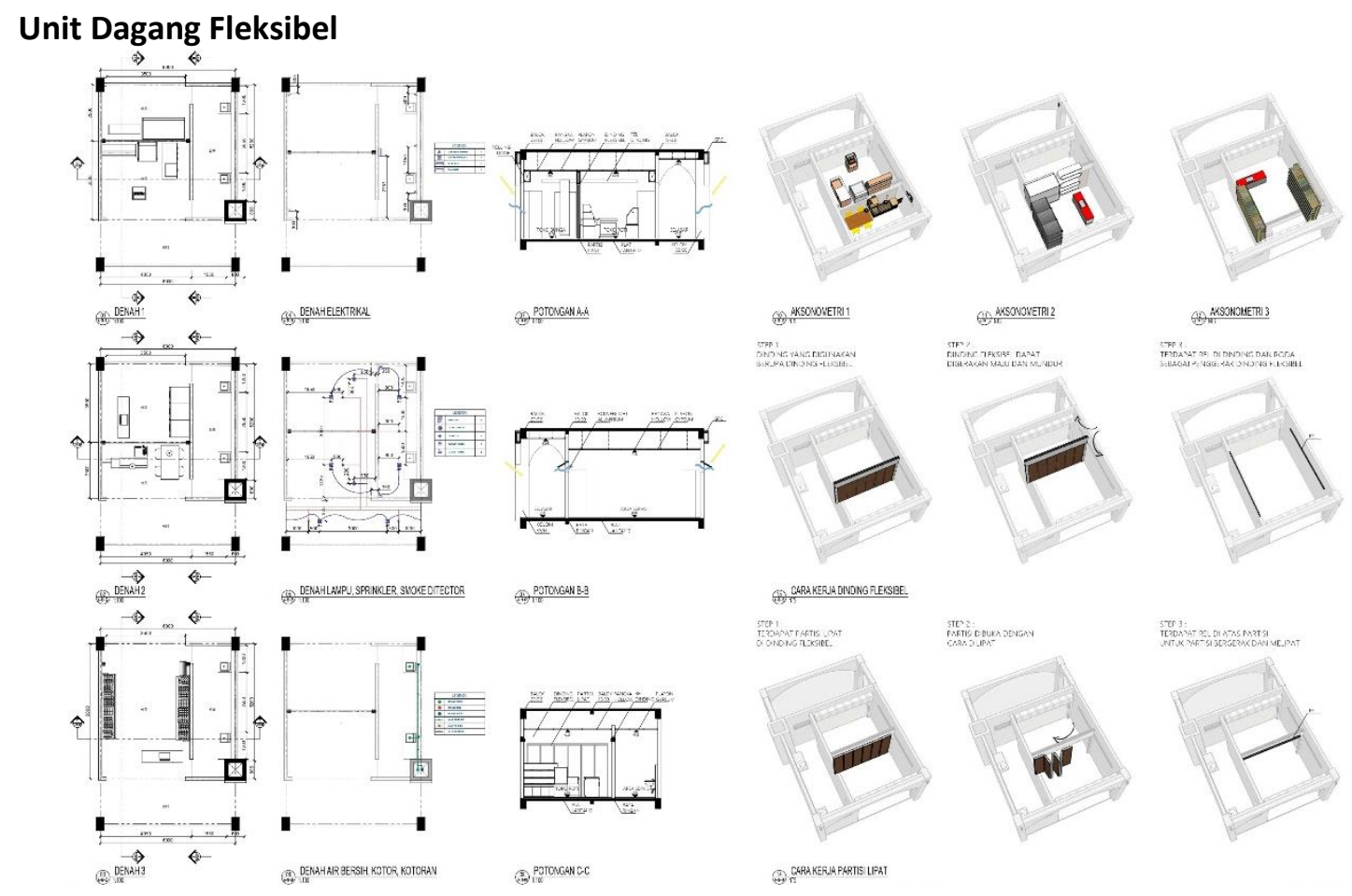

Gambar 12. Diagram Unit Dagang Fleksibel.

Sumber: Hasil Pribadi

Sama seperti unit hunian fleksibel, unit dagang fleksibel ini memiliki luas $36 \mathrm{~m}^{2}$ dan terbagi menjadi 2 zona yaitu zona servis dan zona fleksibel. Pada zona servis terdapat tempat untuk penyimpanan dan cuci, sedangkan zona fleksibel dapat digunakan untuk tempat usaha. Dimana pada zona fleksibel terdapat dinding partisi fleksibel yang dapat digerakan untuk membagi luas tempat usaha sesuai dengan kebutuhan luas aktivitas usahanya.

\section{KESIMPULAN DAN SARAN Kesimpulan}

Kampoeng Pelangi ini dirancang sebagai sebuah kampung vertikal untuk masyarakat berpenghasilan rendah (MBR) dengan tujuan utama yaitu menyediakan hunian yang layak dan berkelanjutan bagi MBR tanpa menghilangkan aktivitas, perilaku, dan karakteristik kampung itu sendiri. Dimana permasalahan yang terjadi adalah Kebudayaan dan tradisi masyarakat sebuah kampung yang kental dengan aktivitas dan kehidupannya semakin pudar setelah perkembangan ke arah hunian-hunian yang vertikal, tertutup dan individualistik. Untuk itu proyek ini hadir untuk memecahkan permasalahan tersebut, dengan ruang - ruang baru yang disediakan sesuai dengan kebutuhan ruang dan aktivitas warga kalianyar diharapkan dapat mampu meningkatkan aspek sosial, ekonomi, dan lingkungan warga Kalianyar mengarah ke pembangunan yang berkelanjutan. Juga dengan desain unit fleksibel yang terdiri dari unit hunian, unit furniture, serta unit dagangnya untuk mengatasi permasalahan kenyamanan tinggal penghuni hunian vertikal dalam beraktivitas pada keterbatasan ruang.

\section{Saran}

Berdasarkan kesimpulan di atas, maka dapat diasampaikan saran bahwa pemerintah harus terus berupaya dalam meningkatkan hunian untuk masyarakat berpenghasilan rendah. Termasuk memperhatikan permasalahan dan kenyamanan yang ada pada hunian vertikal. Diharapkan dengan menggali lagi potensi daerah yang tersedia dapat menjadi keunggulan dan ciri khas dari sebuah hunian. Diharapkan pula untuk tetap mempetahankan aktivitas, perilaku, 
dan karakteristik sebuah daerah sehingga warganya tidak berubah. Sehingga secara bersama sama dapat merasakan manfaat dari pembangunan hunian vertikal yang kiranya dapat berfungsi secara efektif dan efisien.

\section{REFERENSI}

BPS, K. (2019). Kecamatan Tambora Dalam Angka. DKI Jakarta: Badan Pusat Statistik Kota Administrasi Jakarta Barat.

Budiharjo, E. (1992). Sejumlah Masalah Perkampungan Kota. Bandung: Alumni.

Humas. (2021, 01 23). Hasil Sensus Penduduk 2020; BPS: Meski Lambat, Ada Pergeseran Penduduk Antarpulau. Retrieved from Sekretariat Kabinet Republik Indonesia: https://setkab.go.id/hasil-sensus-penduduk-2020-bps-meski-lambat-ada-pergeseranpenduduk-antarpulau/

Katharina, G. (2018, 10 02). Ini 10 Masalah Rumah Susun Versi Pemerintah, Apa Saja? Retrieved from bisnis: https://ekonomi.bisnis.com/read/20181002/49/844640/ini-10masalah-rumah-susun-versi-pemerintah-apa-saja

Khudori, D. (2002). Menuju Kampung Pemerdekaan . Yogyakarta: Yayasan Pondok Rakyat.

Rozak, A. (2017). Kampung Vertikal di Muara Angke Jakarta Dengan Pendekatan Arsitetur Ekologis.

SSLA. (2021, 06 27). Sustainable Development. Retrieved from SSLA: https://www.ssla.co.uk/sustainable-development/

Sudarsono, A. (1983). Pertumbuhan Penduduk Dan Masalah Lingkungan Hidup. Yogyakarta: IKIP Press.

Suminar, E. Y. (2017). Kampung Vertikal Kalianyar dengan Pendekatan Arsitektur Perilaku.

Suryo, M. S. (2017). Konfigurasi Ruang. Analisa Kebutuhan Luas Minimal Pada Rumah Sederhana Tapak Di Indonesia, 120.

Toekio. (2000). Dimensi Ruang dan Waktu. Bandung: Intermatra.

Utina, R. (2008). Pendidikan Lingkungan Hidup dan Konservasi Sumber Daya Alam Pesisir. Gorontalo: UNG Press.

Wikipedia. (2021, 03 22). Ekologi. Retrieved from Wikipedia: https://id.wikipedia.org/wiki/Ekologi

Yu Sing. (2011, 01 10). Keberagaman Kampung Vertikal. Retrieved from Rumah Yusing: http://rumah-yusing.blogspot.com/2011/01/keberagaman-kampung-vertikal.html 